\title{
Conducting Anilate-Based Mixed-Valence Fe(II)Fe(III) Coordination Polymer: Small-Polaron Hopping Model for Oxalate-Type Fe(II)Fe(III) 2D Networks
}

Suchithra Ashoka Sahadevan, Alexandre Abherve', Noemi Monni, Cristina Saenz de Pipaon

José Ramoń Galan-Mascaros, Joaõ C. Waerenborgh, Bruno J. C. Vieira, Pascale Auban-Senzier, Sebastien Pillet, El-Eulmi Bendeif, Pere Alemany, Enric Canadell, Maria Laura Mercuri, and Narcis Avarvari

Laboratoire MOLTECH-Anjou UMR 6200, UFR Sciences, CNRS, Universite' d'Angers, Bat. K, 2 Bd. Lavoisier, 49045 Angers, France

Dipartimento di Scienze Chimiche e Geologiche, Universita degli Studi di Cagliari, I-09042 Monserrato (Cagliari), Italy

Institute of Chemical Research of Catalonia, The Barcelona Institute of Science and Technology (BIST), Avenida Països Catalans 16, 43007 Tarragona, Spain

ICREA, Passeig Lluís Companys 23, 08010 Barcelona, Spain

Centro de Ciencias e Tecnologias Nucleares, Instituto Superior Tecnico, Universidade de Lisboa, 2695-066 Bobadela LRS,

Portugal

Laboratoire de Physique des Solides, UMR 8502, Bat. 510, CNRS-Université Paris-Sud, 91405 Orsay, France

Université de Lorraine, CNRS, CRM2, F-54000 Nancy, France

Departament de Ciencia de Materials i Química Física and Institut de Química Teorica i Computacional (IQTCUB), Universitat de Barcelona, Martí i Franques 1, 08028 Barcelona, Spain

Institut de Ciencia de Materials de Barcelona (CSIC), Campus de la UAB, E-08193 Bellaterra, Spain

* Supporting Information

ABSTRACT: The mixed-valence $\mathrm{Fe}^{\mathrm{II}} \mathrm{Fe}^{\mathrm{III}}$ 2D coordination polymer formulated as [TAG] $\left[\mathrm{Fe}^{\mathrm{II}} \mathrm{Fe}^{\mathrm{III}}(\mathrm{ClCNAn})_{3}\right] \cdot($ solvate $) 1(\mathrm{TAG}=$ tris(amino)-guanidinium, $\mathrm{ClCNAn}^{2-}=$ chlorocyanoanilate dianionic ligand) crystallized in the polar trigonal space group P3. In the solid-state structure, determined both at 150 and at $10 \mathrm{~K}$, anionic $2 \mathrm{D}$ honeycomb layers $\left[\mathrm{Fe}^{\mathrm{II}} \mathrm{Fe}^{\mathrm{III}}(\mathrm{ClCNAn})_{3}\right]^{-}$establish in the ab plane, with an intralayer metal-metal distance of $7.860 \AA$, alternating with cationic layers of TAG. The similar $\mathrm{Fe}-\mathrm{O}$ distances suggest electron delocalization and an average oxidation state of +2.5 for each $\mathrm{Fe}$ center. The cation imposes its $\mathrm{C}_{3}$ symmetry to the structure and engages in intermolecular $\mathrm{N}-\mathrm{H} \cdots \mathrm{Cl}$ hydrogen bonding with the ligand. Magnetic susceptibility characterization

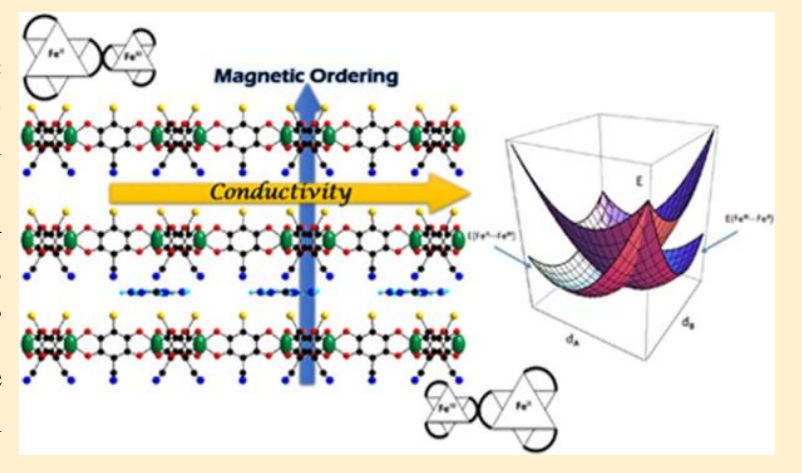
indicates magnetic ordering below $4 \mathrm{~K}$ and the presence of a hysteresis loop at $2 \mathrm{~K}$ with a coercive field of 60 Oe. Mössbauer measurements are in agreement with the existence of Fe $(+2.5)$ ions at RT and statistic charge localization at $10 \mathrm{~K}$. The compound shows semiconducting behavior with the in-plane conductivity of $2 \times 10^{-3} \mathrm{~S} / \mathrm{cm}, 3$ orders of magnitude higher than the perpendicular one. A small-polaron hopping model has been applied to a series of oxalate-type $\mathrm{Fe}^{\mathrm{II}} \mathrm{Fe}^{\mathrm{III}} 2 \mathrm{D}$ coordination polymers, providing a clear explanation on the much higher conductivity of the anilate-based systems than the oxalate ones.

\section{INTRODUCTION}

Molecular materials combining conducting (ח-type, delocalized) and magnetic (d-type, localized) electrons have attracted major interest in molecular science since they can exhibit the coexistence of two distinct physical properties, furnished by the two independent networks, or novel and improved properties when they interact. ${ }^{1}$ In this context, heterobimetallic oxalatebridged compounds have been thoroughly used as a magnetic lattice of multifunctional magnetic materials. ${ }^{2}$ They are formed by anionic networks $\left[\mathrm{M}^{\mathrm{II}} \mathrm{M}^{\mathrm{III}}(\mathrm{ox})_{3}\right]^{-} \quad(\mathrm{ox}=$ oxalate $)$ with magnetic ions linked through bis-bidentate bridging oxalate ligands. The second property is provided by the chargecompensating cation, thus combining the long-range magnetic 
ordering of the oxalate network with paramagnetism, ${ }^{3}$ photochromism, ${ }^{4}$ electrical conductivity, ${ }^{5}$ proton conductivity, ${ }^{6}$ ferroelectricity, ${ }^{7}$ chirality, ${ }^{8}$ or single-molecule magnet behavior. ${ }^{9}$ In recent years, coordination polymers based on the 3,5-disubstituted-2,6-dihydroxy-1,4-benzoquinone $\left(\mathrm{H}_{2} \mathrm{dhbq}\right.$, see Scheme 1), also called anilate ligand in its dianionic

Scheme 1. 2,6-Dihydroxy-1,4-benzoquinone $\left(\mathrm{H}_{2} \mathrm{dhbq}\right)$ and Potassium Chlorocyananilate (KHClCNAn)

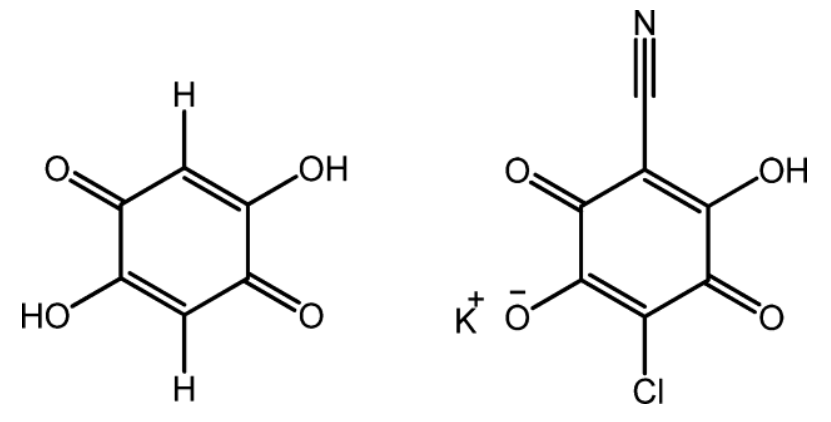

form ( $\mathrm{dhbq}^{2-}$ or $\left.\mathrm{X}_{2} \mathrm{An}^{2-}\right)$, have been thoroughly developed. ${ }^{10}$ They usually present $2 \mathrm{D}$-layered ${ }^{11}$ or $3 \mathrm{D}$-extended networks ${ }^{12}$ with larger cavities than those obtained in oxalate-based coordination polymers due to the larger size of the bridging ligand. More recently, Miyasaka et al. have been able to increase the magnetic ordering temperature in the previously reported ferrimagnet $\left(\mathrm{NBu}_{4}\right)\left[\mathrm{Mn}^{\mathrm{II}} \mathrm{Cr}^{\mathrm{III}}\left(\mathrm{Cl}_{2} \mathrm{An}\right)_{3}\right]\left(\mathrm{Cl}_{2} \mathrm{An}^{2-}=\right.$ chloranilate) from 10 to $40 \mathrm{~K}$. ${ }^{13}$ Taking advantage of the porosity of the material, they inserted $\mathrm{Li}^{+}$ions into the pores of the $2 \mathrm{D}$ network in order to generate a radical $\mathrm{Cl}_{2} \mathrm{An}^{-3-}(\mathrm{S}=1$ / 2) and produce a new exchange interaction between the radical ligand and the metal centers, thus giving further proof of the potential of the anilate ligand to enhance the magnetic coupling in the extended network. In this context, coexistence of electrical conductivity and magnetic ordering in $\mathrm{Fe}^{\mathrm{III}}$ anilatebased coordination polymers has been reported simultaneously by two research groups in $2015 .^{14}$ In both cases, the conducting properties were attributed to the presence of radical anilate bridging ligand species. The role played by the $\mathrm{Fe}^{\mathrm{II}} / \mathrm{Fe}^{\mathrm{III}}$ and $\mathrm{L}^{2-} / \mathrm{L}^{3-}$ mixed valency was further discussed by Robson et al. with a more recent result based on an interpenetrated 3D network of formula $\left(\mathrm{NBu}_{4}\right)\left[\mathrm{Fe}_{2}\left(\mathrm{~F}_{2} \mathrm{An}\right)_{3}\right]$ $\left(\mathrm{F}_{2} \mathrm{An}^{2-}=\right.$ fluoranilate $) .{ }^{12 \mathrm{~d}}$ Another advantage of the anilate ligand is that it can be substituted on the 3 and 6 positions of the aromatic ring by a large variety of substituents. ${ }^{15}$ Recently, the asymmetric chlorocyananilate $\left(\mathrm{ClCNAn}^{2-}\right.$, see Scheme $1)^{16}$ ligand has been combined to the redox-active molecule bis(ethylenedithio)-tetrathiafulvalene (BEDT-TTF) to prepare an organic semiconductor with formula [HClCNAn $]_{2}$ [BEDT$\mathrm{TTF}]^{17}$ and to lanthanide ions in a series of coordination polymers of general formula $\left[\operatorname{Ln}_{2}(\mathrm{ClCNAn})_{3}(\mathrm{DMF})_{6}\right]$. $\left(\mathrm{CH}_{2} \mathrm{Cl}_{2}\right)_{\mathrm{x}}(\mathrm{Ln}=\mathrm{Yb}, \mathrm{x}=0 ; \mathrm{Ln}=\mathrm{Nd}$ or $\mathrm{Er}, \mathrm{x}=1)$ which present NIR emission properties as bulk and nanosheets. ${ }^{18}$ In this work, we investigated this nonsymmetric anilate ligand to prepare the mixed-valence coordination polymer of formula $[\mathrm{TAG}]\left[\mathrm{Fe}^{\mathrm{II}} \mathrm{Fe}^{\mathrm{III}}(\mathrm{ClCNAn})_{3}\right] \cdot$ (solvate) (1), where TAG is the $\mathrm{C}_{3}$-symmetric tris(amino)-guanidinium cation, never used so far in such coordination polymers. Thorough structural characterization and study of the magnetic and conducting properties of this crystalline material are described. Since mixed-valence $\mathrm{Fe}^{\mathrm{II}} \mathrm{Fe}^{\mathrm{III}}$ oxalate-based coordination polymers were previously reported to present a very poor conductivity, we also investigated the origin and mechanism of the transport properties in mixed-valence $\mathrm{Fe}^{\mathrm{II}} \mathrm{Fe}^{\mathrm{III}}$ networks based on oxalate-related bridging ligands, i.e., oxalate, squarate, dhbq ${ }^{2-}$, and $\mathrm{ClCNAn}{ }^{2-}$.

\section{EXPERIMENTAL SECTION}

Tris(amino)-guanidinium chloride (TAGCl) ${ }^{19}$ and potassium chlorocyananilate (KHClCNAn) ${ }^{16}$ were prepared according to the reported procedures. All other chemicals were commercially available and used as received without further purification.

Synthesis of [TAG][Fe" $\left.\mathrm{Fe}^{\prime \prime \prime}(\mathrm{CICNAn})_{3}\right] \cdot$ (solvate) (1). An aqueous solution $(8 \mathrm{~mL})$ of $\mathrm{KHClCNAn}(64 \mathrm{mg}, 0.27 \mathrm{mmol})$ was first placed in the bottom of a test tube, then it was carefully layered a solution of TAGCl (42 mg, $0.3 \mathrm{mmol})$ in a mixture of water $(2 \mathrm{~mL})$ and THF $(2 \mathrm{~mL})$ in the middle, and then a solution of $\mathrm{Fe}\left(\mathrm{ClO}_{4}\right)_{2}$. $\mathrm{xH}_{2} \mathrm{O}(51 \mathrm{mg}, 0.2 \mathrm{mmol})$ in acetone $(3 \mathrm{~mL})$ was added on the top. After 1 week black hexagonal crystals suitable for XRD measurement appeared at the interface. Anal. Calcd for $\mathrm{C}_{22} \mathrm{H}_{67} \mathrm{~N}_{9} \mathrm{O}_{41} \mathrm{Cl}_{3} \mathrm{Fe}_{2}$ : C, 19.84; H, 5.07; N, 9.47. Found: C, 19.32; H, 5.23; N, 9.22. FT-IR (v $\left.\max / \mathrm{cm}^{-1}\right): 2221\left(\mathrm{v}_{\mathrm{C} \equiv \mathrm{N}}\right), 1631,1492\left(\mathrm{v}_{\mathrm{C}-\mathrm{O}}+\mathrm{v}_{\mathrm{C}-\mathrm{C}}\right), 869\left(\delta_{\mathrm{C}-\mathrm{Cl}}+\right.$ $\left.\mathrm{v}_{\mathrm{C}-\mathrm{O}}\right)$.

Structural Characterization. Data collection was performed at $150 \mathrm{~K}$ on an Agilent Supernova diffractometer with $\mathrm{Cu} \mathrm{Ka}(\lambda=$ $1.54184 \AA$ A). A single crystal of 1 was mounted on a glass fiber loop using a viscous hydrocarbon oil to coat the crystal and then transferred directly to the cold nitrogen stream for data collection. The structure was solved by direct methods with the SIR97 program and refined against all $\mathrm{F}^{2}$ values with the SHELXL-97 program using the WinGX graphical user interface. All non-hydrogen atoms were refined anisotropically except for the $\mathrm{C}$ and $\mathrm{N}$ atoms from the cationic entity $\mathrm{CN}_{6} \mathrm{H}_{9}{ }^{+}$, and hydrogen atoms were placed in calculated positions and refined isotropically with a riding model. The program SQUEEZE from PLATON was used to calculate the potential solvent-accessible void volume and the nature of the disordered solvent molecules. It has indicated a total void space of $885 \AA^{3}$ and 293 electrons/cell. This corresponds to 29 molecules of water that have been inserted in the formula of the compound. A summary of crystallographic data and refinement results are listed in Table 1.

Data collection was performed at $10 \mathrm{~K}$ on a SuperNova Microfocus diffractometer equipped with a two-dimensional ATLAS detector using Mo Ka radiation $(\lambda=0.71073 \AA)$ and a Helijet He open-flow cryosystem. The unit-cell determination and data reduction were performed using the CrysAlisPRO program suite (Rigaku Oxford Diffraction, 2017) on the full data set. The data have been indexed using the trigonal setting with cell parameters $a=b=13.5493(16) \AA$ and $c=9.484(3) \AA$. In addition, the diffraction pattern showed the presence of very weak $\left(\begin{array}{llll}1 / 3 & 1 / 3 & 1 / 3\end{array}\right)$ superstructure reflections, which were not taken into account in the structure determination. The corresponding crystal structure was refined on $\mathrm{F}^{2}$ by weighted full matrix least-squares methods using the SHELXL program (Sheldrick, 2008). All non-hydrogen atoms were refined anisotropically except for the $\mathrm{C}$ and $\mathrm{N}$ atoms from the cationic entity $\mathrm{CN}_{6} \mathrm{H}_{9}^{+}$, and hydrogen atoms were placed in calculated positions and refined isotropically with a riding model. The program SQUEEZE from PLATON was used to calculate the potential solvent-accessible void volume and the nature of the disordered solvent molecules.

CCDC-1858728 $(150 \mathrm{~K})$ and $1858527(10 \mathrm{~K})$ contain the supplementary crystallographic data for this paper.

Raman Measurements. The Raman spectrum of 1 was carried out at room temperature on single crystals by using a micro Raman spectrometer (Horiba Labram 300) equipped with a $\mathrm{He}-\mathrm{Ne}$ laser $(\lambda$ $=632.81 \mathrm{~nm})$ in the $80-2000 \mathrm{~cm}^{-1}$ range with a $20 \mathrm{LWD}$ objective $\left(<0.25 \mathrm{~mW} / \mu \mathrm{m}^{2}\right.$ on the crystal). A $180^{\circ}$ reflective geometry was adopted. The samples were mounted on a glass microscope slide, and the scattering peaks were calibrated against a Si standard $(v=520.7$ $\mathrm{cm}^{-1}$ ). A typical spectrum was collected with a $300 \mathrm{~s}$ time constant at $<1 \mathrm{~cm}^{-1}$ resolution and averaged over three scans. The KHClCNAn FT-Raman spectrum was recorded at room temperature on a capillary tube by using a Bruker RFS/100 FT-Raman spectrometer equipped 
Table 1. Crystallographic Data for Compound 1 at 150 and $10 \mathrm{~K}$

\begin{tabular}{|c|c|c|}
\hline & $150 \mathrm{~K}$ & $10 \mathrm{~K}$ \\
\hline empirical formula & $\mathrm{C}_{22} \mathrm{H}_{67} \mathrm{~N}_{9} \mathrm{O}_{41} \mathrm{Cl}_{3} \mathrm{Fe}_{2}$ & $\mathrm{C}_{22} \mathrm{H}_{67} \mathrm{~N}_{9} \mathrm{O}_{41} \mathrm{Cl}_{3} \mathrm{Fe}_{2}$ \\
\hline fw & 1331.90 & 1331.90 \\
\hline cryst color & black & black \\
\hline cryst size $\left(\mathrm{mm}^{3}\right)$ & $0.20 \times 0.20 \times 0.05$ & $0.22 \times 0.19 \times 0.06$ \\
\hline wavelength $(\AA)$ & 1.54184 & 0.71073 \\
\hline cryst syst, Z & trigonal, 1 & trigonal, 1 \\
\hline space group & $\mathrm{P} 3$ & $\mathrm{P} 3$ \\
\hline$a(\AA)$ & $13.616(2)$ & $13.5493(16)$ \\
\hline$b(\AA)$ & $13.616(2)$ & $13.5493(16)$ \\
\hline$c(\AA)$ & $9.430(4)$ & $9.484(3)$ \\
\hline$\alpha(\mathrm{deg})$ & 90 & 90 \\
\hline$\beta$ (deg) & 90 & 90 \\
\hline$Y(\operatorname{deg})$ & 120 & 120 \\
\hline$v\left(n^{3}\right.$ & 1J1t.1(0) & IJvivive \\
\hline$\rho_{\text {calcd }}\left(\mathrm{g} \cdot \mathrm{cm}^{-3}\right)$ & 1.461 & 1.467 \\
\hline$\mu(\mathrm{Cu} \mathrm{K \alpha})\left(\mathrm{mm}^{-1}\right)$ & 5.994 & 0.653 \\
\hline$\theta$ range $(\mathrm{deg})$ & $3.75-73.74$ & $2.15-26.36$ \\
\hline data collected & 3465 & 8947 \\
\hline data unique & 2610 & 3976 \\
\hline data obsd & 1360 & 1612 \\
\hline $\mathrm{R}$ (int) & 0.0459 & 0.0604 \\
\hline no. of parameters/restraints & $140 / 4$ & $125 / 2$ \\
\hline $\mathrm{R} 1(\mathrm{~F}),{ }^{a} \mathrm{I}$ > $2 \sigma(\mathrm{I})$ & 0.0395 & 0.0715 \\
\hline $\mathrm{wR} 2\left(\mathrm{~F}^{2}\right),{ }^{\mathrm{b}}$ all data & 0.1258 & 0.2391 \\
\hline$S\left(F^{2}\right),{ }^{C}$ all data & 0.891 & 1.095 \\
\hline
\end{tabular}

with a Nd:YAG laser $(\lambda=1064 \mathrm{~nm})$ in a backscattering geometry. No sample decomposition was observed during the experiments. The choice of the FT-Raman spectrometer was required because of the fluorescence of the ligand under $\mathrm{He}-\mathrm{Ne}$ laser irradiation.

Magnetic Measurements. Magnetic measurements were carried out on polycrystalline samples with a Quantum Design MPMS-XL-7T SQUID magnetometer (Quantum Design, Inc., San Diego, CA, USA). Magnetic measurements (dc) were carried out under an applied field of 1000 Oe. Zero-field-cooled/field-cooled/remanent magnetization (ZFC/FC/RM) were collected under an applied field of 25 Oe. Alternating current susceptibility measurements were carried out with an alternating magnetic field of 3.95 Oe in the 1$1500 \mathrm{~Hz}$ frequency range.

Mössbauer Spectroscopy. Mössbauer spectra were collected in transmission mode using a conventional constant-acceleration spectrometer and a $25 \mathrm{mCi}{ }^{57} \mathrm{Co}$ source in a $\mathrm{Rh}$ matrix. The velocity scale was calibrated using a-Fe foil. Isomer shifts, IS, are given relative to this standard at room temperature. The low-temperature spectrum was collected in a bath cryostat with the sample in He exchange gas. The absorber was obtained by gently packing the powdered sample into a perspex holder. The spectra were fitted to Lorentzian lines using a nonlinear least-squares method.

Single-Crystal Transport Measurements. Electrical transport measurements were performed on hexagonal-shaped single crystals. Gold wires (17 $\mu \mathrm{m}$ diameter) were glued with silver paste either on two edges or on both faces of the crystals (for conductivity measurements parallel and perpendicular to the 2D planes, respectively). Two-probe dc measurements were performed applying a constant voltage in the range $0-5 \mathrm{~V}$ and measuring the current using a Keithley 6487 Picoammeter/Voltage Source. Low temperature was provided by a homemade cryostat equipped with a $4 \mathrm{~K}$ pulse tube.

Theoretical Calculations. Density functional theory (DFT)based calculations were carried out adopting the hybrid TPSSh functional, ${ }^{20}$ which has been shown to give good high-spin-low-spin relative energies for spin-crossover complexes involving iron ${ }^{21}$ and the standard double- $\zeta+$ polarization basis set $6-31 \mathrm{G}(\mathrm{d}) .{ }^{22}$ Geometries were optimized forcing a $D_{3}$ symmetry and a high-spin configuration using the Gaussian 09 code. ${ }^{23}$

\section{RESULTS AND DISCUSSION}

Synthesis. The synthesis of the mixed-valence compound 1 differs from that of the heterobimetallic oxalate and anilatebased coordination polymers. In such cases, the tetrabutylammonium salt of (tris-oxalato)metal(III) or (tris-anilato)metal(III) complex was first prepared and isolated. The precursor thus obtained was then reacted with the second metal salt by diffusion techniques to grow the bimetallic extended network. Here we have slowly diffused a solution of $\mathrm{Fe}^{\mathrm{II}} \mathrm{ClO}_{4} \cdot \mathrm{xH}_{2} \mathrm{O}$ and a solution of tris(amino)-guanidinium chloride (TAGCl) into a solution of KHClCNAn. Due to the partial oxidation of the $\mathrm{Fe}^{\mathrm{II}}$ ions under aerobic conditions, black hexagonal crystals of the $\mathrm{Fe}^{\mathrm{II}} \mathrm{Fe}^{\mathrm{III}}$ compound 1 were obtained after 1 week.

Crystal Structure. Compound 1 crystallizes in the trigonal polar space group $\mathrm{P} 3$. The structure is formed by anionic $2 \mathrm{D}$ layers of formula $\left[\mathrm{Fe}^{\mathrm{II}} \mathrm{Fe}^{\mathrm{III}}(\mathrm{ClCNAn})_{3}\right]^{-}$in the ab plane, alternating with cationic layers of TAG. The anionic layer presents the well-known honeycomb structure, which is similar to other extended oxalate ${ }^{24}$ and anilate-based 2D networks. ${ }^{11 \mathrm{a}-\mathrm{e}}$ It consists of a hexagonal layer with $\mathrm{Fe}^{\mathrm{II}}$ and $\mathrm{Fe}^{\mathrm{III}}$ ions linked through the anionic bis-bidentate $\mathrm{ClCNAn}^{2-}$ ligands (Figures 1 and S1 and S2). As usual for this type of 2D networks, the two crystallographically independent metal centers present alternated chirality ( $\Delta$ configuration for Fe1 and $\Lambda$ configuration for $\mathrm{Fe} 2$ in the crystal used to solve the structure). The intralayer metal-metal distance is $7.860 \AA$. The average $\mathrm{Fe}-\mathrm{O}$ distances are very similar between both metal centers (2.037(12) A for Fe1 and 2.047(13) A for Fe2, see Table 2), which may indicate an electron delocalization and an average oxidation state of +2.5 for each Fe center (vide infra). The cationic layer is formed by one crystallographically independent TAG cation and water molecules. The TAG cation has an occupancy of $1 / 3$, which is one-half of the Fe atoms, and is located only on one-half of the vertices of the hexagons. The structure of the cation is planar, with the C8$\mathrm{N} 2$ and N2-N3 distances (1.394(15) and 1.558(17) respectively, see Table $\mathrm{S} 1$ ) in agreement with distances reported in the literature for other TAG-based compounds. ${ }^{25}$ Anionic and cationic layers present intermolecular $\mathrm{H}$-bonding interactions between the terminal amino groups of the TAG cation and the chloro substituents of the anilate ligands (Figure 1). The distance between two anionic layers corresponds to the value of the $c$ parameter $(9.430(4) \AA)$. The cationic and anionic 2D layers are eclipsed, leading to hexagonal channels along the $c$ axis which are filled only by solvent molecules. When compared to the previously reported anilate-based layered coordination polymers, ${ }^{11 \mathrm{a}-\mathrm{h}}$ here the use of the smaller cation results in a drastic increase of the void space inside the hexagonal channels $\left(885 \AA^{3}\right)$. This represents $58 \%$ of the total volume, thus increasing the porosity of the $2 \mathrm{D}$ material (Figure S3). As a consequence, the compound shows a fast release of the solvent molecules after filtration, and the nature of these solvent molecules could not be attributed without ambiguity. In order to reach a good reliability factor and since 293 electrons per hexagonal cavity were determined by the SQUEEZE program, 29 molecules of water have been integrated in the empirical formula (see Table 1). However, 

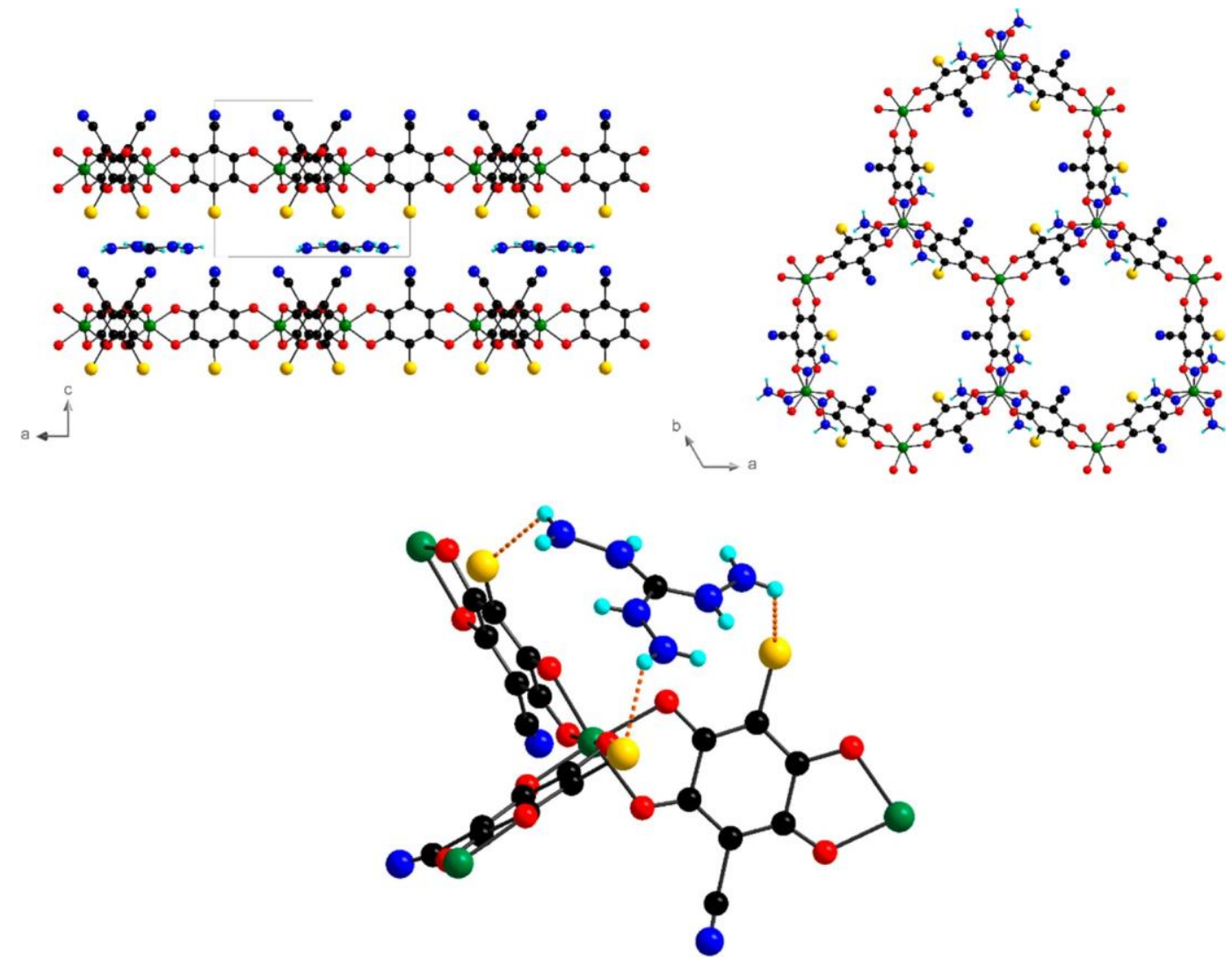

Figure 1. Structure of 1 in the ac plane (top left) and in the ab plane (top right). H-bonding intermolecular interactions (dashed lines) between the cationic and the anionic layers (bottom). Color code: C, black; H, cyan; O, red; N, blue; Cl, yellow; Fe, green.

Table 2. Selected Fe-O Bond Distances $(\AA)$ in Compound 1

$\begin{array}{ccc}\mathrm{Fe}-\mathrm{O} \text { distances } & 150 \mathrm{~K}(\AA) & 10 \mathrm{~K}(\AA) \\ \mathrm{Fe} 1-\mathrm{O} 1 & 2.000(6) & 1.937(7) \\ \mathrm{Fe} 1-\mathrm{O} 2 & 2.086(6) & 2.103(7) \\ \mathrm{Fe} 2-\mathrm{O} 3 & 2.073(7) & 2.117(7) \\ \mathrm{Fe} 2-\mathrm{O} 4 & 2.018(6) & 1.974(7)\end{array}$

TGA analysis could not confirm the precise nature of the solvent molecules (Figure S4). Since a mixture of three solvents has been used during the synthesis (water, THF, and acetone), the formula of the compound should be defined as $[\mathrm{TAG}]\left[\mathrm{Fe}^{\mathrm{II}} \mathrm{Fe}^{\mathrm{III}}(\mathrm{ClCNAn})_{3}\right] \cdot($ solvate).

By comparison with the $150 \mathrm{~K}$ crystal structure, the overall honeycomb 2D structural architecture in the trigonal P3 space group is retained at $10 \mathrm{~K}$. Accordingly, the asymmetric unit still contains two symmetrically independent iron sites (Fe1 and $\mathrm{Fe} 2$ ). The unit cell parameters and unit cell volumes are slightly lower at $10 \mathrm{~K}$, owing to usual thermal contraction effects. The intralayer metal-metal distance $(7.8243(7) \AA)$ and average $\mathrm{Fe}-\mathrm{O}$ distances (2.020(14) $\AA$ for $\mathrm{Fe} 1$ and 2.043(14) $\AA$ for $\mathrm{Fe} 2$ ) are not significantly different from the $150 \mathrm{~K}$ values. Accordingly, the $10 \mathrm{~K}$ crystal structure does not evidence a specific ordering of the $\mathrm{Fe}^{\mathrm{II}}$ and $\mathrm{Fe}^{\mathrm{III}}$ ions on the symmetrically independent $\mathrm{Fe} 1$ and $\mathrm{Fe} 2$ sites. We can therefore consider that in this description the $\mathrm{Fe}^{\mathrm{II}}$ and $\mathrm{Fe}^{\mathrm{III}}$ ions are spatially distributed and disordered over the two sites. As mentioned in the Experimental Section, very weak superstructure reflections were detected on the diffraction pattern, which indicates that the exact structural ordering may be more complex than this description in the P3 space group. However, the quality of the X-ray diffraction data, and especially the weakness of the superstructure reflections, does not allow going further. The current description leads to two $\mathrm{Fe}^{\mathrm{II}}$ and two $\mathrm{Fe}^{\mathrm{III}}$ different local environments in the crystal, which is consistent with the results from Mössbauer spectroscopy (vide infra).

Raman Spectroscopy. Raman spectra are valuable probes to investigate the oxidation state of coordinated benzoquinone derivatives. ${ }^{26}$ Therefore, in order to confirm the oxidation state of the bridging ligand a Raman study at room temperature was performed and a comparison between the Raman spectra of 1 and the free KHClCNAn ligand is reported in Figure 2.

The strong and broad band centered at ca. $1574 \mathrm{~cm}^{-1}$ can be assigned to a $\mathrm{v}(\mathrm{C}+\mathrm{C})+\mathrm{v}(\mathrm{C} \boldsymbol{\mathrm { O }})$ combination band, and the significant observed downshift from $1627 \mathrm{~cm}^{-1}$ for the free ligand can be attributed to a weakened double-bond character of these terminal groups because of the coordination with the metal ion; the weak band centered at ca. $1675 \mathrm{~cm}^{-1}$ present in the free ligand spectrum can be assigned to the $\mathrm{v}(\mathrm{C} \$ \mathrm{O})$ vibration mode for the uncoordinated $\mathrm{C} \uparrow \mathrm{O}$ groups of the free ligand and in fact is not observed in 1 . The two bands observed in the $1400-1250 \mathrm{~cm}^{-1}$ region are assigned to the $\mathrm{v}(\mathrm{C}-\mathrm{C})+$ $\mathrm{v}(\mathrm{C}-\mathrm{O})$ combination band and $\mathrm{v}(\mathrm{C}-\mathrm{C})$ vibration, respectively, and according to Harris et al. ${ }^{14 \mathrm{c}}$ confirm the assignment of ligand oxidation state as dianionic $\mathrm{ClCNAn}^{2-}$, supporting structural findings. The observed band at $592 \mathrm{~cm}^{-1}$ can be assigned to a $\mathrm{v}(\mathrm{Fe}-\mathrm{O})+\mathrm{v}(\mathrm{C}-\mathrm{C})$ combination stretching mode, as already found in previously reported dianionic anilate-based honeycomb-like networks. ${ }^{14 a}$ No bands can be unambiguously assigned to $\mathrm{Fe}^{\mathrm{II}}-\mathrm{O}$ and $\mathrm{Fe}^{\mathrm{III}}-\mathrm{O}$ vibrational 


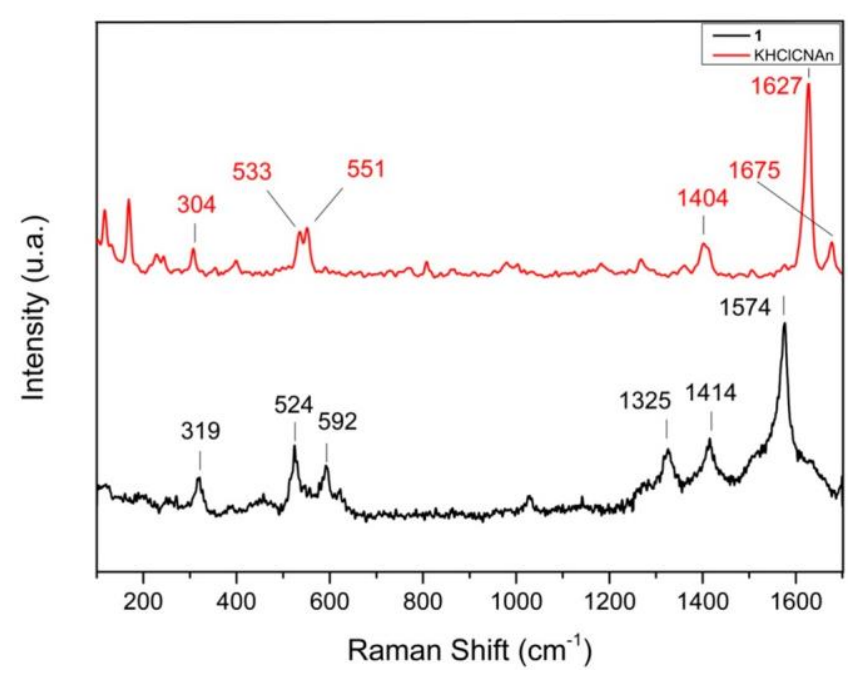

Figure 2. Comparison of Raman spectra of 1 and the KHClCNAn ligand, performed at room temperature with a $\mathrm{He}-\mathrm{Ne}$ laser $(\lambda=$ $632,81 \mathrm{~nm})$ and a Nd:YAG $(\lambda=1064 \mathrm{~nm})$, respectively.

modes, thus supporting extensive electron delocalization between the Fe centers in 1 at room temperature, as clearly shown by Mössbauer spectra (vide infra).

Magnetic Properties. The magnetic properties were measured on a polycrystalline sample of 1 . The product of the molar magnetic susceptibility times the temperature $\left(X_{m} T\right)$ presents a value of $9.7 \mathrm{emu} \cdot \mathrm{K} \cdot \mathrm{mol}^{-1}$ at $300 \mathrm{~K}$, which corresponds to the expected spin-only value $(7.38 \mathrm{emu} \cdot \mathrm{K}$. $\mathrm{mol}^{-1}$ ) with a $\mathrm{g}=2.2$ (Figure 3 ). When the temperature is

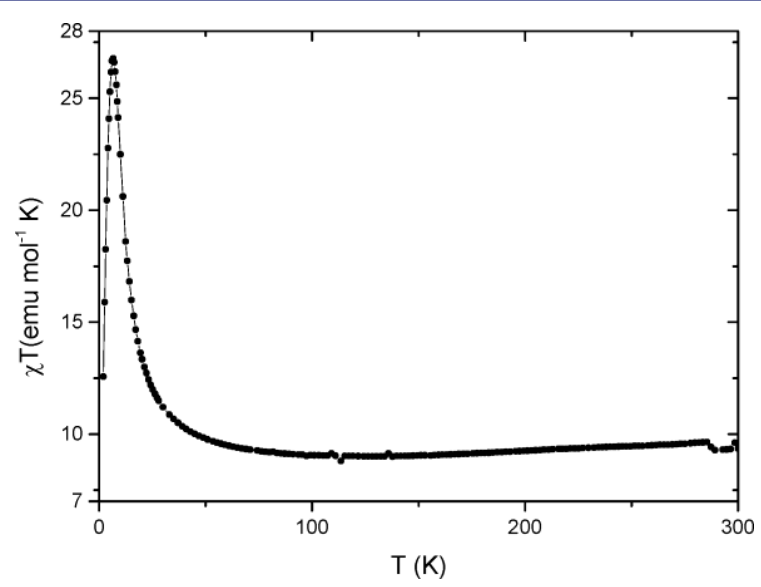

Figure 3. Temperature dependence of the product of the molar magnetic susceptibility times the temperature $\left(X_{m} T\right)$ of 1 under an applied field of $1000 \mathrm{Oe}$.

lowered, $\mathrm{X}_{\mathrm{m}} \mathrm{T}$ slightly decreases, suggesting weak antiferromagnetic interactions between paramagnetic centers through the anilate bridges. Below $50 \mathrm{~K}, \mathrm{X}_{\mathrm{m}} \mathrm{T}$ increases until reaching a value of $\sim 27 \mathrm{emu} \cdot \mathrm{K} \cdot \mathrm{mol}^{-1}$ at $7 \mathrm{~K}$, followed by a sharp decrease at lower temperatures. This suggests a magnetic ordering, which was confirmed by zero-field-cooled/field-cooled (ZFC/ FC) and remnant magnetization measurements under a very low magnetic field (Figure S5). The ZFC and FC plots diverge below $3.5 \mathrm{~K}$, indicating the appearance of an irreversibility or memory effect. The remnant magnetization becomes nonnegligible at the same temperature, confirming the existence of spontaneous magnetization below this temperature.
The magnetic ordering was also confirmed by susceptibility measurements under alternating magnetic field (ac susceptibility, Figure 4a). This shows the appearance of an out-ofphase signal and an ordering temperature $T_{c}$ slightly dependent on the frequency, which can be observed for both superparamagnets and spin glasses. ${ }^{27}$ The fitting of this frequencydependent behavior to a simple Arrhenius model (Figure 4b) yields parameters with no physical meaning, including a $\mathrm{T}_{0}=$ $10^{-12}$, very different to what is found in superparamagnets (or single-molecule magnets, with values of $\mathrm{T}_{0}$ between $10^{-8}$ and $\left.10^{-10} \mathrm{~s}\right) .^{28}$ This $\mathrm{T}_{0}$ value falls within the range reported for magnetic spin-glass systems $\left(10^{-12}-10^{-14} \mathrm{~s}\right)^{29}$ and is then consistent with a glassy magnet behavior as observed in many 2D magnetic materials. ${ }^{30}$ Moreover, the Mydosh parameter $\varphi$, calculated from the ac data, ${ }^{31}$ has a value of 0.08 , in good agreement with the expected values for a noncanonical spin glass. ${ }^{14 a, 32}$

Isothermal magnetization measurements at low temperatures show a fast increase of the magnetization at low fields that becomes more gradual at higher fields (Figure 5). The sharp increase at low fields $(\mathrm{H}<1000 \mathrm{Oe})$ also supports the appearance of spontaneous magnetization due to strong interactions between metal centers. The magnetization saturates at higher fields reaching $\sim 5 \mu_{\mathrm{B}}$, far from the expected $9 \mu_{\mathrm{B}}$ for parallel alignment of spin carriers. This confirms the ferrimagnetic nature of the spontaneous magnetization that stabilizes a ground state with an intermediate spin, characteristic of a glassy ferrimagnet as suggested by the initial decrease in the $\mathrm{X}_{\mathrm{m}} \mathrm{T}$ at high temperatures. An additional proof of the magnetic ordering is the presence of a hysteresis loop at $2 \mathrm{~K}$ with a coercive field of 60 Oe.

Mössbauer spectroscopy has been used to confirm the oxidation state of the $\mathrm{Fe}$ metal centers (Figure 6). At $10 \mathrm{~K}$ three broad absorption peaks are observed. They may be interpreted by two quadrupole doublets. However, due to the large width of the absorption peaks a significantly better fit is obtained with four quadrupole doublets. The estimated isomer shift, IS, and quadrupole splitting, QS, are consistent with the presence of high-spin $\mathrm{Fe}^{3+}$ and high-spin $\mathrm{Fe}^{2+}$ in octahedral coordination by anionic oxygen atoms. ${ }^{33}$ The estimated relative areas indicate that approximately one-half of the $\mathrm{Fe}$ cations are in the +3 state and the other half in the +2 state. The two doublets observed for each oxidation state are consistent with the occupation of $\mathrm{Fe}(1)$ and $\mathrm{Fe}(2)$ crystallographic sites by both $\mathrm{Fe}^{2+}$ and $\mathrm{Fe}^{3+}$. The room-temperature spectrum shows only one asymmetric doublet with IS and QS consistent with an average oxidation state of $+2.5 .^{34}$ The temperature dependence of the Mössbauer spectra of the anilate coordination polymer is similar to the behavior observed for other mixed-valence iron compounds, namely, molecular complexes. ${ }^{35}$ The intermediate isomer shift at room temperature corresponds to a charge-delocalized state on the Mössbauer spectroscopy time scale of $\sim 10^{-7}$ s, i.e., a chargetransfer frequency $\geq 10^{8} \mathrm{~s}^{-1}$. As the temperatures decreases, the frequency of charge delocalization gradually decreases, and at $10 \mathrm{~K}$ the $\mathrm{Fe}^{2+}$ and $\mathrm{Fe}^{3+}$ states are localized when compared to the Mössbauer effect time window (i.e., the lifetime of the $\mathrm{Fe}^{2+}$ and $\mathrm{Fe}^{3+}$ states becomes longer than $10^{-7} \mathrm{~s}$ ).

Transport Properties. Since a mixed-valence state and electron delocalization have been evidenced in 1 , we could expect this coordination polymer to present transport properties; therefore, electrical conductivity measurements have been carried out on single crystals. The hexagonal shape of the 


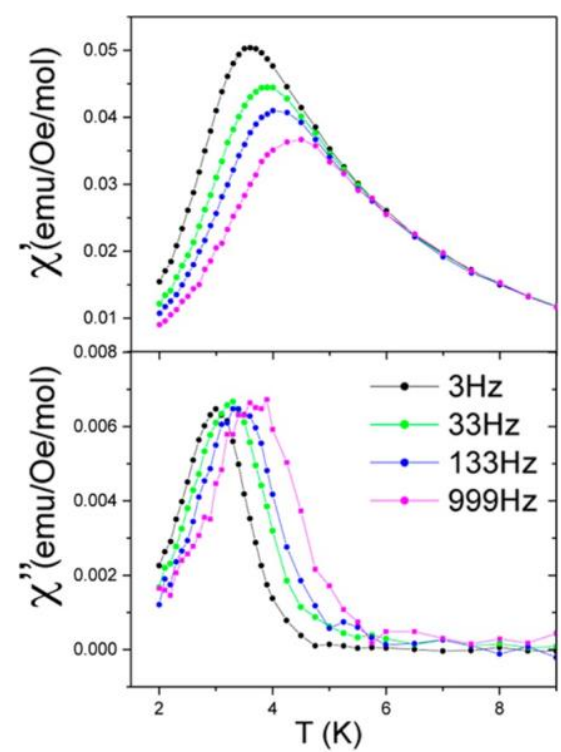

(a)

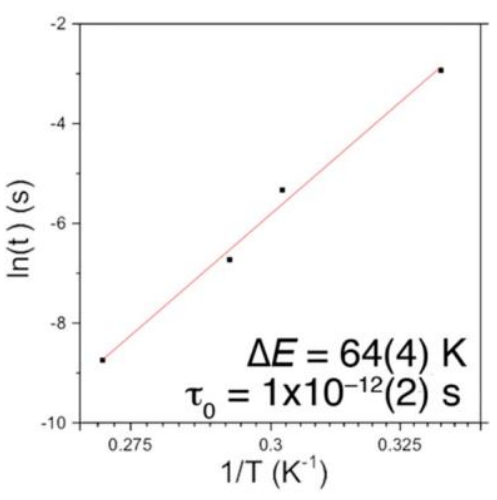

(b)

Figure 4. (a) Temperature dependence of the in-phase ( $\left.X^{\prime}\right)$ and out-of-phase ( $\left.X^{\prime \prime}\right)$ ac susceptibility of 1, and (b) Arrhenius plot for the frequency dependence of the position of the peak in $X^{\prime \prime}$ vs $1 / T$.

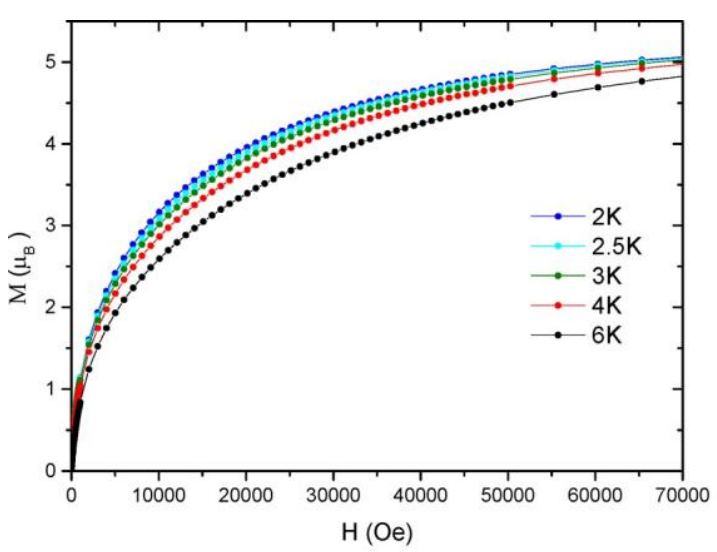

(a)

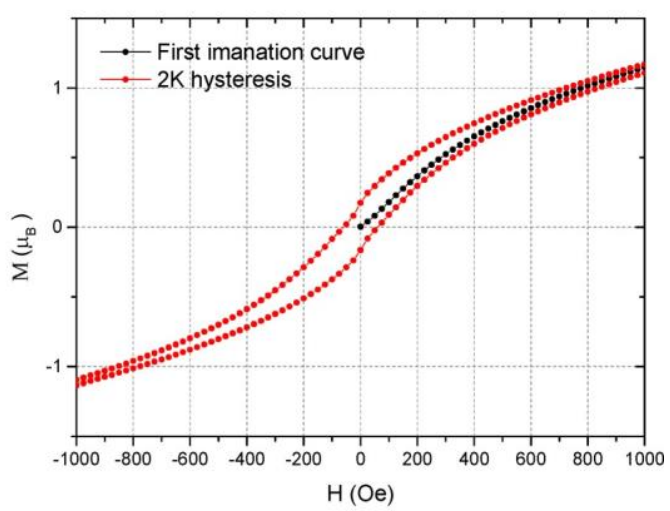

(b)

Figure 5. (a) Isothermal magnetization of 1 at different temperatures and (b) magnetic hysteresis loop at $2 \mathrm{~K}$.

crystals allows determining the direction of the $\{001\}$ plane and then to measure the conductivity parallel $\left(\sigma_{\|}\right)$and perpendicular $\left(\sigma_{\perp}\right)$ to the $2 \mathrm{D}$ layers, corresponding to the $\mathrm{ab}$ plane. The temperature dependence of the resistivity indicates that 1 is a semiconductor (Figure 7). The parallel roomtemperature conductivity value $\sigma_{\|}$is about $2 \times 10^{-3} \mathrm{~S} / \mathrm{cm}$, almost 3 orders of magnitude higher than the perpendicular room-temperature conductivity $\sigma\left(7 \times 10^{-6} \mathrm{~S} / \mathrm{cm}\right)$.

Relationship between the Electrical Conductivity and the Nature of the Bridging Ligand. The fairly good conductivity of compound 1 as well as of the few recently reported anilato-based $\mathrm{Fe}^{\mathrm{II}} \mathrm{Fe}^{\mathrm{III}}$ coordination polymers ${ }^{11 \mathrm{~g}, 14 \mathrm{~b}}$ is in sharp contrast with the low conductivity found for the oxalate-based ones. ${ }^{36}$ To gain insight into the origin of the good conductivity in our anilate-based coordination polymer and to point out the crucial role of the bridging ligand, we have undertaken a theoretical study on the electron transfer in 2D $\mathrm{Fe}^{\mathrm{II}} \mathrm{Fe}^{\mathrm{III}}$ networks based on bis(bidentate) oxalate-type ligands in which we consider the conductivity dominated by thermally activated small-polaron hopping. We are interested in a simple, pragmatic approach, highlighting the role of the bridging ligand, and in this comparative work, we decided to focus on four ligands: oxalate, squarate $\left(\mathrm{C}_{4} \mathrm{O}_{4}{ }^{2-}\right.$, dianion of 3,4dihydroxycyclobut-3-ene-1,2-dione), dhbq ${ }^{2-}$, and $\mathrm{ClCNAn}^{2-}$, with different electron delocalization capabilities.

The basic reasoning behind the small-polaron hopping approach to the electron transfer process in either discrete or extended mixed-valence systems ${ }^{37,38}$ is qualitatively illustrated in Figure 8. Consider a system formed by two separated highspin $\mathrm{Fe}^{\mathrm{II}} \mathrm{L}_{6}\left(\mathrm{t}_{2 \mathrm{~g}}{ }^{4} \mathrm{e}_{\mathrm{g}}{ }^{2}\right)$ and high-spin $\mathrm{Fe}^{\mathrm{III}} \mathrm{L}_{6}\left(\mathrm{t}_{2 \mathrm{~g}}{ }^{3} \mathrm{e}_{\mathrm{g}}{ }^{2}\right)$ complexes in close proximity. Although the electron transfer between them is between levels of the $\mathrm{Fe}_{2 \mathrm{~g}}$ orbital set, which are formally nonbonding, such transfer leads, in general, to an increase/ decrease of the $\mathrm{M}-\mathrm{L}$ distances in the $\mathrm{Fe}^{\mathrm{II}} / \mathrm{Fe}^{\mathrm{III}} \mathrm{L}_{6}$ units due to the expansion/contraction of the electron cloud. As a consequence of the fact that electrons move much faster than nuclei, the much faster electron transfer occurs in such a way that the geometry cannot change during the process and the system cannot exchange thermal energy with the surroundings. In other words, before the electron transfer 


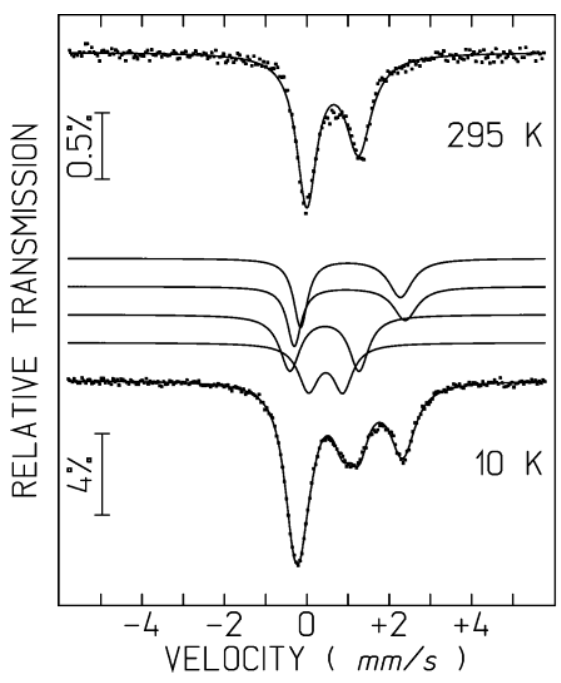

(a)

\begin{tabular}{ccccc}
\hline $\mathrm{T}$ & $\begin{array}{c}\mathrm{IS} \\
(\mathrm{mm} / \mathrm{s})\end{array}$ & $\begin{array}{c}\mathrm{QS} \\
(\mathrm{mm} / \mathrm{s})\end{array}$ & $\mathrm{I}(\%)$ & $\begin{array}{c}\mathrm{Fe} \\
\text { state }\end{array}$ \\
\hline \hline $295 \mathrm{~K}$ & 0.74 & 1.26 & $100 \%$ & $\mathrm{Fe}^{2.5+}$ \\
\hline \multirow{3}{*}{$10 \mathrm{~K}$} & 0.57 & 0.83 & $24 \%$ & $\mathrm{Fe}^{3+}$ \\
& 0.54 & 1.68 & $29 \%$ & $\mathrm{Fe}^{3+}$ \\
& 1.15 & 2.69 & $22 \%$ & $\mathrm{Fe}^{2+}$ \\
& 1.17 & 2.42 & $25 \%$ & $\mathrm{Fe}^{2+}$ \\
\hline
\end{tabular}

(b)

Figure 6. (a) Mössbauer spectra of 1 taken at 295 and $10 \mathrm{~K}$, and (b) estimated parameters from the spectra. Lines over the experimental points are the calculated functions. On the spectrum taken at $10 \mathrm{~K}$ this function is the sum of four quadrupole doublets shown slightly shifted for clarity. IS, isomer shift relative to metallic a-Fe at $295 \mathrm{~K}$; QS, quadrupole splitting; I, relative areas. Estimated errors are $<0.02 \mathrm{~mm} / \mathrm{s}$ for IS and QS and $<2 \%$ for I.

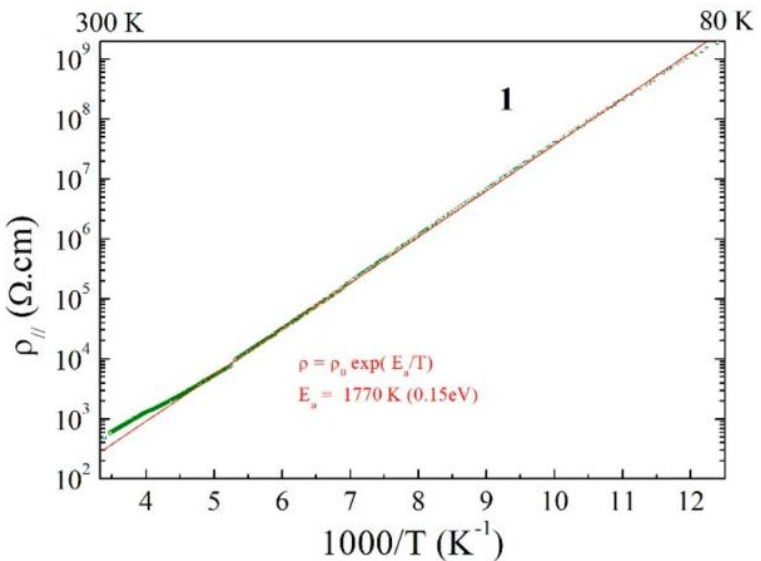

(a)

\begin{tabular}{ccc}
\hline & $\rho(\mathrm{k} \Omega . \mathrm{cm})$ & $\sigma(\mathrm{S} / \mathrm{cm})$ \\
\hline \hline$/ /$ & 0.5 & $2.10^{-3}$ \\
\hline$\perp$ & 143 & $7.10^{-6}$ \\
\hline
\end{tabular}

(b)

Figure 7. (a) Electrical resistivity $\rho_{\|}$plotted as $\log \rho_{\|}$versus the inverse temperature, measured with a $4 \mathrm{~V}$ voltage applied in the ab plane. Red line is the fit to the data with the law $\rho=\rho_{0} \exp \left(E_{a} / T\right)$ giving the activation energy $E_{a}$. (b) Room-temperature resistivity $(\rho)$ and conductivity $(\sigma)$ values measured along $(\|)$ and perpendicular $(\perp)$ to the $2 \mathrm{D}$ layers.

can actually take place a $\mathrm{Fe}^{\mathrm{III}}$ species with the $\mathrm{Fe}^{\mathrm{II}}$ geometry (and viceversa) must be created. This rearrangement is however energetically unfavorable, so that the electron transfer will only occur when as a result of some vibrational process the two Fe centers reach equal coordination geometries (see Figure 8a). Thus, to understand the differences in thermally activated conductivity one must focus on the evaluation of the energetic cost of such "equalization" of the two sites.

A simple yet usually very insightful analysis relies on the assumption that the structural distortion around each center may be described by a simple harmonic oscillator $E_{i}=1 / 2 k_{i}\left(d_{i}\right.$ $\left.-d_{0}\right)^{2}$, where $k_{i}$ is the force constant, $d_{i}$ the Fe-L distance, and $\mathrm{d}_{0}$ its equilibrium value. Within this approximation the energy of the whole system is $E_{\text {tot }}=k_{\text {III }}\left(d_{\mathrm{A}}-d_{I I I}\right)^{2}+k_{I I}\left(d_{B}-d_{I I}\right)^{2}$, where for the sake of simplicity the $1 / 2$ factors have been included in the force constants. Here let us assume that complex $\mathrm{A}$ is in the $\mathrm{Fe}^{\mathrm{III}}$ state and complex $\mathrm{B}$ in the $\mathrm{Fe}^{\mathrm{II}}$ state, but there is a totally equivalent expression interchanging $A$ and $B$. If we plot the two energy surfaces $E_{\text {tot }}\left(d_{A}, d_{B}\right)$ we see that they cross along the line $d_{A}=d_{B}$ (Figure $8 b$ ). The initial and final configurations (respectively, top and bottom configurations in Figure 8a) correspond to minima in the lower surface and the structures for which $d_{A}=d_{B}$ to the crossing seam. The situation is more conveniently analyzed by using a contour plot of the bottom surface (Figure 8c), obtained by joining the two bottom halves of the two intersecting surfaces.

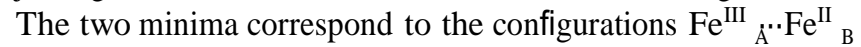
(zone noted as $\mathrm{F}$ in Figure $8 \mathrm{c}$ ) and $\mathrm{Fe}^{\mathrm{II}}{ }_{\mathrm{A}} \cdot \mathrm{FF}^{\mathrm{III}}{ }_{\mathrm{B}}$ (noted as I). The point on the $d_{A}=d_{B}$ line for which the total energy is minimal $(\mathrm{M})$ is found by taking the derivative of the energy function with $d_{A}=d_{B}=d_{M}$ and equating it to zero. It is found that $\mathrm{d}_{\mathrm{M}}=\left(\mathrm{k}_{\mathrm{II}} \mathrm{d}_{\mathrm{II}}+\mathrm{k}_{\text {III }} \mathrm{d}_{\text {III }}\right) /\left(\mathrm{k}_{\mathrm{II}}+\mathrm{k}_{\text {III }}\right)$ and the corresponding energy $E_{M}=\left(k_{I I} k_{I I I} /\left(k_{I I}+k_{I I I}\right)\right)\left(d_{I I}-d_{I I I}\right)^{2}$. In other words, the minimal energy required to make the coordination environ- 


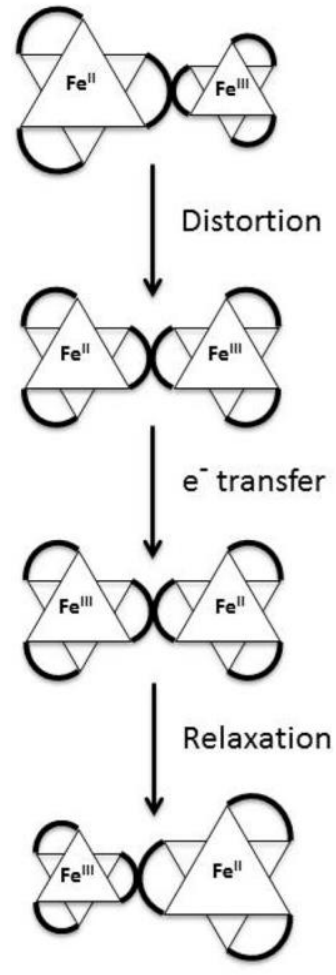

(a)

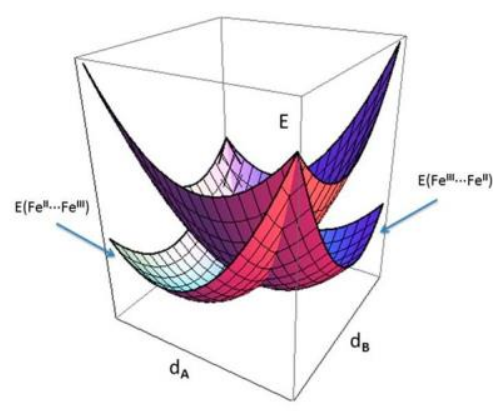

(b)

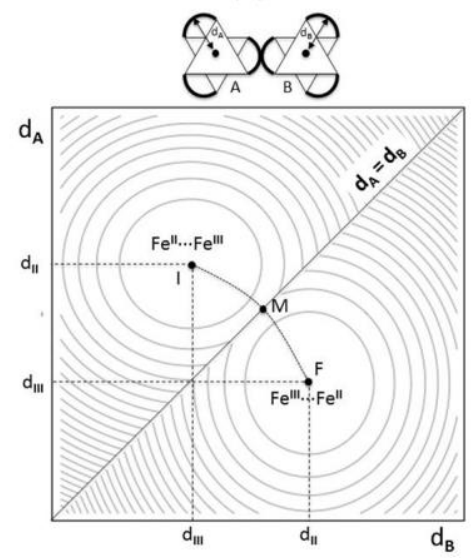

(c)
Figure 8. (a) Schematic representation of the three consecutive steps during the electron transfer with two neighboring pseudooctahedral $\mathrm{Fe}$ (chelate) $)_{3}$ centers shown along the $\mathrm{C}_{3}$ axis. (b) 3D plot of the energy surface $E_{\text {tot }}$ as a function of $d_{A}$ and $d_{B}$. (c) Contour plot of the bottom surface from the $E_{\text {tot }}$ plot displayed in $b$.

ments on both $\mathrm{Fe}$ centers equal, that is, the height of the barrier for thermally activated electron transfer, depends basically on the difference squared between the radii of the $\mathrm{Fe}^{\mathrm{III}}$ and $\mathrm{Fe}^{\mathrm{II}}$ coordination environments in their equilibrium geometries.

The model can be more simply depicted by using a cut through the two surfaces in which we plot the energy along the dotted path joining the two minima through the $\mathrm{M}$ point, which is taken as the origin (Figure 9). This gives two parabolas corresponding to the energy of the whole system with either an $\mathrm{Fe}^{\mathrm{II}} \mathrm{Fe}^{\mathrm{III}}$ or an $\mathrm{Fe}^{\mathrm{III}} \mathrm{Fe}^{\mathrm{II}}$ configuration and crossing at the $\mathrm{M}$ point. Note that when the two complexes are not totally isolated from their surroundings, the energy necessary to distort the complexes has an additional contribution from the environment. This is particularly important in the case of 2D lattices where the distortion of one site contributes to the distortion of all its neighboring sites. This contribution is usually included considering a generic parameter $\lambda$, which is the vertical ionization energy from one minimum to the other curve or in other words the energy necessary to transfer the electron from A to B without considering a previous structural equalization of both centers. The barrier for thermal electron transfer in the absence of interaction (i.e., the energy difference between the minima and the crossing point of the two curves) is then simply $\lambda / 4$. In the real case there is always some degree of electronic interaction between the two sites and a gap, $2 \mathrm{~V}_{\mathrm{AB}}$, is opened at point $\mathrm{M}$, and the barrier for thermal electron transfer is consequently lowered to $\lambda / 4-\mathrm{V}_{\mathrm{AB}}$. Unfortunately, there is no simple way to evaluate $\mathrm{V}_{\mathrm{AB}}$ without having recourse to long and costly computations, but since we are here interested only in looking for trends when the bridging ligand is changed, it seems safe to consider that $\lambda / 4$ will be the leading term in the energy barrier, so that we can make our comparisons neglecting the effects of the nature of the ligands on $\mathrm{V}_{\mathrm{AB}}$.

It is now easy to relate the main parameters (mainly structural) of this simple model to the transport measurements. The diagram in Figure 9 is completely general and applicable to any electron transfer process. In an extended system, when the dimensions of the zone where the necessary atomic rearrangement controlling the electron transfer occurs are of the order of the coordination sphere of a single site as in the present case, one talks about a system with small polarons. ${ }^{38}$ The polaron energy, $W_{P}$, is the energy gained when the system relaxes after addition of one electron. In this small-polaron scenario the conductivity is dominated by thermally activated electron hopping with the mobility given by the equation $\mu=$

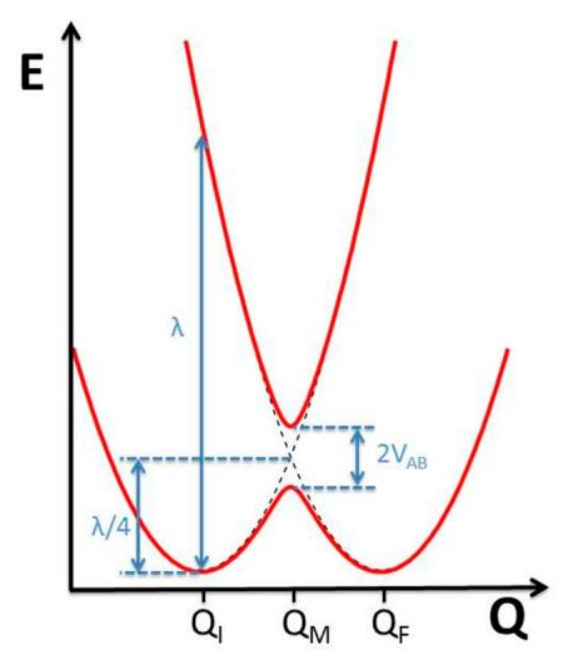

(a)

$\begin{array}{cc}E_{I I I} & 0 \\ d_{I I I} & 2.764 \\ k_{I I I} & 489 \\ E_{I I} & 208 \\ d_{I I} & 2.914 \\ k_{I I} & 403 \\ d_{M} & 2.832 \\ (\Delta d)^{2} & 0.022 \\ F & 221 \\ W_{H} & 4.93\end{array}$

4.93

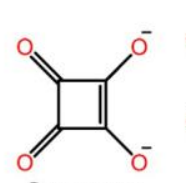

Squarate

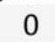

2.639

241

159

2.752

180

2.687

0.013

103

1.33

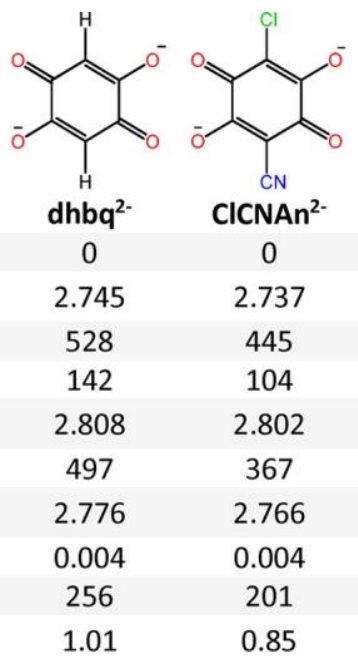

(b)

Figure 9. (a) Energy plot for a $\mathrm{Fe}^{\mathrm{II}} \mathrm{Fe}^{\mathrm{III}}$ to $\mathrm{Fe}^{\mathrm{III}} \mathrm{Fe}^{\mathrm{II}}$ electron transfer process. (b) Calculated parameters for the four studied bridging ligands. Distances are expressed in Angstroms, energies in $\mathrm{kcal} \cdot \mathrm{mol}^{-1}$, and $\mathrm{k}$ and $\mathrm{F}$ in $\mathrm{kcal} \cdot \mathrm{mol}^{-1} \cdot \AA^{-2}$. 
$\mu_{0} e^{-W_{H} / k}$, where $W_{H}$ is the electron hopping barrier, i.e., the energy cost to reach the geometry under which the electron transfer is possible. As far as it is assumed that the variation of energy is a quadratic function of the structural parameters, the energy cost per site to reach the "equalization" geometry is $1 / 4$ $\mathrm{W}_{\mathrm{P}}$, and taking into account that there are two sites involved in the transfer, it follows that $W_{H}=1 / 2 W_{P}$. Since according to the Franck-Condon principle the energy to optically excite one electron from one to the other site (i.e., $\lambda$ in Figure 9) is twice the polaron energy it follows that $\mathrm{W}_{\mathrm{H}}=1 / 2 \quad \mathrm{~W}_{\mathrm{P}}=\lambda / 4$. Therefore, $\mathrm{W}_{\mathrm{H}}=\mathrm{E}_{\mathrm{M}}=\mathrm{F}\left(\mathrm{d}_{\mathrm{II}}-\mathrm{d}_{\mathrm{III}}\right)^{2}$, with $\mathrm{F}=\mathrm{k}_{\mathrm{II}} \mathrm{k}_{\mathrm{III}} /\left(\mathrm{k}_{\mathrm{II}}+\mathrm{k}_{\mathrm{III}}\right)$ and $d_{M}=\left(k_{I I} d_{I I}+k_{I I I} d_{I I I}\right) /\left(k_{I I}+k_{I I I}\right)$. In that way it is possible to correlate the transport $\left(\mathrm{W}_{\mathrm{H}}\right)$ and structural $\left(\mathrm{k}_{\mathrm{II}}, \mathrm{k}_{\mathrm{III}}, \mathrm{d}_{\mathrm{II}}\right.$, and $\mathrm{d}_{\text {III }}$ ) features for a series of compounds.

How are these parameters tuned by the nature of the bridging ligand? The values of $\mathrm{k}_{\mathrm{II}}, \mathrm{k}_{\mathrm{III}}, \mathrm{d}_{\mathrm{II}}$, and $\mathrm{d}_{\mathrm{III}}$ can be evaluated from density functional calculations (DFT). We carried out structural optimizations of $\mathrm{Fe}^{\mathrm{II}} \mathrm{L}_{3}$ and $\mathrm{Fe}^{\mathrm{III}} \mathrm{L}_{3}$ complexes with the four ligands oxalate, squarate, $\mathrm{dhbq}^{2-}$, and $\mathrm{ClCNAn}^{2-}$ using the TPSSh functional, which is known to give good high-spin-low-spin relative energies for spincrossover complexes involving iron. ${ }^{21}$ The geometries were optimized forcing a $D_{3}$ symmetry and a high-spin configuration. In that way we obtained the $d_{M-L}$ parameter which is the distance between the $\mathrm{Fe}$ atom and the midpoint to the closest $\mathrm{C}-\mathrm{C}$ bonds (between the $\mathrm{C}$ atoms bonded to the coordinating $\mathrm{O}$ atoms) which corresponds to $\mathrm{d}_{\mathrm{II}}$ or $\mathrm{d}_{\mathrm{III}}$ of the above discussion. Once the optimal $d_{M-L}$ parameter for each $\mathrm{Fe}^{\mathrm{II}}$ and each $\mathrm{Fe}^{\mathrm{III}}$ complex was found, the values of $\mathrm{k}_{\mathrm{II}}$ or $\mathrm{k}_{\mathrm{III}}$ were obtained by reoptimizing the structure for fixed $d_{M-L} \pm \delta$ values and fitting the energy to a second-order polynomial. The results for the four ligands are reported in Figure 9b.

According to the data in Figure $9 \mathrm{~b} \mathrm{~W}_{\mathrm{H}}=0.214,0.057,0.044$, and $0.037 \mathrm{eV}$ for oxalate, squarate, $\mathrm{dhbq}^{2-}$, and $\mathrm{ClCNAn}{ }^{2-}$ respectively. Despite the simplicity of the approach, these numbers are very reasonable when compared with $W_{H}$ estimations based on experimental data for $\mathrm{Fe}^{\mathrm{II}} \mathrm{Fe}^{\mathrm{III}}$ solids like magnetite $(\sim 0.15 \mathrm{eV})^{38}$ and partially substituted ferrites $(\sim 0.11 \mathrm{eV})^{39}$ which are in between those calculated for oxalate and the other three ligands. Thus, we believe that the simple approach captures the essence of the electron transfer process, although the activation energies are smaller than the experimental ones. This is not unexpected since the Fe sites are immersed in a quite rigid $2 \mathrm{D}$ network, which must lead to a noticeable increase in the parameter $\lambda$ and hence in the barrier estimated here by $\lambda / 4$. According to the values in Figure $9 b$ electrons should be much less mobile in oxalate networks than in anilate ones, which is in good agreement with experimental observations. $^{36,11 \mathrm{f}, 14 \mathrm{~b}}$ What is the reason for this finding? The $F$ values for the oxalate ligands are in between those for both the $\mathrm{dhbq}^{2-}$ and the $\mathrm{ClCNAn}^{2-}$ ones, yet $\mathrm{W}_{\mathrm{H}}$ is five times larger. It is clear that the factor determining the large difference is $(\Delta d)^{2}$, i.e., the square of the difference in the $\mathrm{d}$ values for $\mathrm{Fe}$ in the two oxidation states. Because of the quadratic dependence, this term has an overwhelming influence on the final value of $\mathrm{W}_{\mathrm{H}}$. Comparing the $\mathrm{d}_{\mathrm{II}}$ and $\mathrm{d}_{\mathrm{III}}$ distances for the oxalate, $\mathrm{dhbq}^{2-}$, and ClCNAn ${ }^{2-}$ ligands in Figure $9 \mathrm{~b}$ it is clear that whereas the $d_{\text {III }}$ values are fairly similar, $d_{\text {II }}$ for the oxalate ligand is markedly larger than those for the $\mathrm{dhbq}^{2-}$ and $\mathrm{ClCNAn}^{2-}$ ligands. Thus, the determining factor for the lower conductivity of the oxalate systems lies in the difficulty to cope with the extra electron of the high-spin $\mathrm{Fe}^{\mathrm{II}}$ situation. The occurrence of extensive delocalization through the benzene ring of $\mathrm{dhbq}^{2-}$ and $\mathrm{ClCNAn}^{2-}$ acts as a buffer for the electronic rearrangement needed by the presence of the extra electron. Note that when the ligands are more similar, the $F$ factor depending on the force constants may become the key factor. According to Figure $9 \mathrm{~b}$ this is, for instance, the case when comparing the $\mathrm{dhbq}^{2-}$ and $\mathrm{ClCNAn}^{2-}$ ligands. The squarate ligand is also associated with a small $\mathrm{W}_{\mathrm{H}}$ value, not much different from those of the $\mathrm{dhbq}^{2-}$ and $\mathrm{ClCNAn}{ }^{2-}$ ligands. However, the $(\Delta d)^{2}$ term is intermediate between those of the oxalate and $\mathrm{dhbq}^{2-}$ and $\mathrm{ClCNAn}^{2-}$ pair of ligands. Clearly, in that case the $\mathrm{F}$ term plays an important role. Both the geometrical constraints imposed by the four-member ring as well as the delocalization in the central part of the ligand influence the electron transfer tendency.

We thus conclude that the present approach provides a simple, yet insightful, model to rationalize the transport results for these $\mathrm{Fe}^{\mathrm{II}} \mathrm{Fe}^{\mathrm{III}}$ mixed-valence coordination polymers and that the polymers based on the $\mathrm{dhbq}^{2-}$ and $\mathrm{ClCNAn}^{2-}$ ligands rank among the most effective ones in promoting the electron delocalization through a small-polaron hopping mechanism.

\section{CONCLUSIONS}

The mixed-valence $\mathrm{Fe}^{\mathrm{II}} \mathrm{Fe}^{\mathrm{III}} 2 \mathrm{D}$ coordination polymer [TAG]$\left[\mathrm{Fe}^{\mathrm{II}} \mathrm{Fe}^{\mathrm{III}}(\mathrm{ClCNAn})_{3}\right]$ based on the asymmetric chlorocyanoanilate ligand and containing, for the first time in such 2D networks, the tris(amino)-guanidinium (TAG) cation has been synthesized and crystallized in the polar noncentrosymmetric space group $P 3$ thanks to the $\mathrm{C}_{3}$ symmetry of the cation and its ability to engage in intermolecular hydrogen bonding with the chlorine atoms of the ligand. Magnetic susceptibility measurements in combination with Mössbauer spectroscopy are indicative of a spin-glass behavior with magnetic ordering below $4 \mathrm{~K}$ and the presence of intermediate $\mathrm{Fe}(+2.5)$ oxidation state at $\mathrm{RT}$ and charge localization $\mathrm{Fe}^{\mathrm{II}} \mathrm{Fe}^{\mathrm{III}}$ at 10 $\mathrm{K}$, with a statistic occupational crystallographic site according to the $10 \mathrm{~K}$ Mössbauer spectra, also confirmed by the X-ray structure at $10 \mathrm{~K}$. Single-crystal electron transport measurements in the 2D plane and perpendicular on it show semiconducting behavior of the material with a rather high RT value of $2 \times 10^{-3} \mathrm{~S} / \mathrm{cm}$ for the in-plane conductivity, much higher than the one reported in the oxalate-based $2 \mathrm{D} \mathrm{Fe}^{\mathrm{II}} \mathrm{Fe}^{\mathrm{III}}$ coordination polymers. In order to shed light on this difference and on the electron transport mechanism on these fast developing multifunctional families of $2 \mathrm{D}$ coordination polymers, the small-polaron hopping approach to the electron transfer process has been applied to a series of mixed-valence $\mathrm{Fe}^{\mathrm{II}} \mathrm{Fe}^{\mathrm{III}}$ oxalate-related coordination polymers containing as bridging ligands oxalate ${ }^{2-}$, squarate ${ }^{2-}, \mathrm{dhbq}^{2-}$, and ClCNAn ${ }^{2-}$. The results are clearly indicative of a much lower electron hopping barrier in the anilate complexes than in oxalates.

These results open the way toward the use of the TAG cation in such multifunctional binuclear/bimetallic transition metal or lanthanide coordination polymers, possibly endowed with multiferroic properties thanks to the crystallization in polar space groups. Moreover, the mechanism of electron transport in the mixed-valence $\mathrm{Fe}^{\mathrm{II}} \mathrm{Fe}^{\mathrm{III}}$ coordination polymers with bridging oxalate-type ligands has been disclosed, pointing out the higher "elasticity" of the anilate network compared to the oxalate one. 


\section{ASSOCIATED CONTENT}

\section{Supporting Information}

The Supporting Information is available free of charge on the ACS Publications website at DOI: 10.1021/jacs.8b08032.

Full experimental section including description of the synthesis and characterization of all new materials and all of the techniques employed in the research reported here (PDF)

(CIF)

(CIF)

\section{AUTHOR INFORMATION}

Corresponding Authors

*p.alemany@ub.edu

*canadell@icmab.es

*mercuri@unica.it

*narcis.avarvari@univ-angers.fr

ORCID

José Ramón Galan-Mascaros: 0000-0001-7983-9762

Enric Canadell: 0000-0002-4663-5226

Maria Laura Mercuri: 0000-0002-4816-427X

Narcis Avarvari: 0000-0001-9970-4494

\section{Author Contributions}

${ }^{\S}$ S.A.S. and A.A. contributed equally to this work.

Notes

The authors declare no competing financial interest.

\section{ACKNOWLEDGMENTS}

The work in France was supported by the CNRS, the University of Angers, the Erasmus program (mobility grant to N.M.), the RFI Regional project LUMOMAT (grant to A.A., project ASCO MMM), and the PIA project "Lorraine Universite d'Excellence" (reference ANR-15-IDEX-04-LUE). This work was supported in Italy by the Fondazione di Sardegna-Convenzione triennale tra la Fondazione di Sardegna e gli Atenei Sardi, Regione Sardegna-L.R. 7/2007 annualità 2016-DGR 28/21 del 17.05.2015 "Innovative Molecular Functional Materials for Environmental and Biomedical Applications" and INSTM. Work in Spain was supported by the Spanish Ministerio de Economia y Competitividad (Grants FIS2012-37549-C05-05, FIS2015-64886-C5-4-P, CTQ201564579-C3-3-P, and CTQ2015-71287-R) and Generalitat de Catalunya (2014SGR301, 2017SGR797, and XRQTC and the CERCA program). E.C. acknowledges support of the Spanish MINECO through the Severo Ochoa Centers of Excellence Program under Grant SEV-2015-0496. J.C.W. and B.J.C.V. acknowledge Fundaçao para a Ciencia e a Tecnologia (FCT, Portugal) through the project UID/Multi/04349/2013.

\section{REFERENCES}

(1) (a) Coronado, E.; Day, P. Chem. Rev. 2004, 104, 5419-5448. (b) Enoki, T.; Miyazaki, A. Chem. Rev. 2004, 104, 5449-5478. (c) Kobayashi, H.; Cui, H. B.; Kobayashi, A. Chem. Rev. 2004, 104, 5265-5288. (d) Kurmoo, M.; Graham, A. W.; Day, P.; Coles, S. J.; Hursthouse, M. B.; Caulfield, J. L.; Singleton, J.; Pratt, F. L.; Hayes, W.; Ducasse, L.; Guionneau, P. J. Am. Chem. Soc. 1995, 117, 1220912217. (e) Martin, L.; Turner, S. S.; Day, P.; Mabbs, F. E.; McInnes, E. J. L. Chem. Commun. 1997, 15, 1367-1368. (f) Rashid, S.; Turner, S. S.; Day, P.; Howard, J. A. K.; Guionneau, P.; McInnes, E. J. L.; Mabbs, F. E.; Clark, R. J. H.; Firth, S.; Biggs, T. J. Mater. Chem. 2001, 11, 2095-2101. (g) Uji, S.; Shinagawa, H.; Terashima, T.; Yakabe, T.; Terai, Y.; Tokumoto, M.; Kobayashi, A.; Tanaka, H.; Kobayashi, H.
Nature 2001, 410, 908-910. (h) Fujiwara, H.; Fujiwara, E. Nakazawa, Y.; Narymbetov, B. Zh.; Kato, K.; Kobayashi, H.; Kobayashi, A.; Tokumoto, M.; Cassoux, P. J. Am. Chem. Soc. 2001, 123, 306-314. (i) Coronado, E.; Falvello, L. R.; Galan-Mascaros, J. R.; Gimenez-Saiz, C.; Gomez-García, C. J.; Lauhkin, V. N.; PerezBenítez, A.; Rovira, C.; Veciana, J. Adv. Mater. 1997, 9, 984-987. (j) Madalan, A. M.; Canadell, E.; Auban-Senzier, P.; Branzea, D.; Avarvari, N.; Andruh, M. New J. Chem. 2008, 32, 333-339. (k) Pop, F.; Allain, M.; Auban-Senzier, P.; Martínez-Lillo, J.; Lloret, F.; Julve, M.; Canadell, E.; Avarvari, N. Eur. J. Inorg. Chem. 2014, 2014, 38553862.

(2) Clemente-Leon, M.; Coronado, E.; Martí-Gastaldo, C.; Romero, F. M. Chem. Soc. Rev. 2011, 40, 473-497.

(3) (a) Clemente-Leon, M.; Coronado, E.; Galan-Mascaros, J. R.; Gomez-García, C. J. Chem. Commun. 1997, 1727-1728. (b) Coronado, E.; Galan-Mascaros, J. R.; Gomez-García, C. J.; Martínez-Agudo, J. M. Adv. Mater. 1999, 11, 558-561. (c) Coronado, E.; GalanMascaros, J. R.; Gomez-García, C. J.; Ensling, J.; Gütlich, P. Chem. Eur. J. 2000, 6, 552-563.

(4) (a) Benard, S.; Yu, P.; Audiere, J. P.; Riviere, E.; Clement, R.; Guilhem, J.; Tchertanov, L.; Nakatani, K. J. Am. Chem. Soc. 2000, 122, 9444-9454. (b) Aldoshin, S. M.; Sanina, N. A.; Minkin, V. I.; Voloshin, N. A.; Ikorskii, V. N.; Ovcharenko, V. I.; Smirnov, V. A.; Nagaeva, N. K. J. Mol. Struct. 2007, 826, 69-74.

(5) (a) Coronado, E.; Galan-Mascaros, J. R.; Gomez-García, C. J.; Laukhin, V. Nature 2000, 408, 447-449. (b) Alberola, A.; Coronado, E.; Galan-Mascaros, J. R.; Gimenez-Saiz, C.; Gomez-García, C. J. J. Am. Chem. Soc. 2003, 125, 10774-10775. (c) Galan-Mascaros, J. R.; Coronado, E.; Goddard, P. A.; Singleton, J.; Coldea, A. I.; Wallis, J. D.; Coles, S. J.; Alberola, A. J. Am. Chem. Soc. 2010, 132, 9271-9273. (d) Coronado, E.; Galan-Mascaros, J. R.; Gomez-García, C. J.; Martínez-Ferrero, E.; Van Smaalen, S. Inorg. Chem. 2004, 43, 48084810. (e) Zhang, B.; Zhang, Y.; Zhu, D. Chem. Commun. 2012, 48, 197-199.

(6) (a) Okawa, H.; Shigematsu, A.; Sadakiyo, M.; Miyagawa, T.; Yoneda, K.; Ohba, M.; Kitagawa, H. J. Am. Chem. Soc. 2009, 131, 13516-13522. (b) Pardo, E.; Train, C.; Gontard, G.; Boubekeur, K.; Fabelo, O.; Liu, H.; Dkhil, B.; Lloret, F.; Nakagawa, K.; Tokoro, H.; Ohkoshi, S.-I.; Verdaguer, M. J. Am. Chem. Soc. 2011, 133, 1532815331. (c) Sadakiyo, M.; Okawa, H.; Shigematsu, A.; Ohba, M.; Yamada, T.; Kitagawa, H. J. Am. Chem. Soc. 2012, 134, 5472-5475. (d) Okawa, H.; Sadakiyo, M.; Yamada, T.; Maesato, M.; Ohba, M.; Kitagawa, H. J. Am. Chem. Soc. 2013, 135, 2256-2262.

(7) (a) Endo, T.; Akutagawa, T.; Noro, S. I.; Nakamura, T. Dalton Trans 2011, 40, 1491-1496. (b) Pardo, E.; Train, C.; Liu, H.; Chamoreau, L.-M.; Dkhil, B.; Boubekeur, K.; Lloret, F.; Nakatani, K.; Tokoro, H.; Ohkoshi, S.-i.; Verdaguer, M. Angew. Chem., Int. Ed. 2012, 51, 8356-8360.

(8) (a) Andres, R.; Gruselle, M.; Malezieux, B.; Verdaguer, M.; Vaissermann, J. Inorg. Chem. 1999, 38, 4637-4646. (b) Andres, R.; Brissard, M.; Gruselle, M.; Train, C.; Vaissermann, J.; Malezieux, B.; Jamet, J. P.; Verdaguer, M. Inorg. Chem. 2001, 40, 4633-4640. (c) Clemente-Leon, M.; Coronado, E.; Dias, J. C.; Soriano-Portillo, A.; Willett, R. D. Inorg. Chem. 2008, 47, 6458-6463. (d) Train, C.; Gheorghe, R.; Krstic, V.; Chamoreau, L. M.; Ovanesyan, N. S.; Rikken, G. L. J. A.; Gruselle, M.; Verdaguer, M. Nat. Mater. 2008, 7, 729-734. (e) Train, C.; Nuida, T.; Gheorghe, R.; Gruselle, M.; Ohkoshi, S. J. Am. Chem. Soc. 2009, 131, 16838-16843. (f) Gruselle, M.; Li, Y.; Ovanesyan, N.; Makhaev, V.; Shilov, G.; Mushenok, F.; Train, C.; Aldoshin, S. Chirality 2013, 25, 444-448.

(9) ,Clemente-Leon, M.; Coronado, E.; Gomez-García, C. J.; LopezJorda, M.; Camon, A.; Repolles, A.; Luis, F. Chem. - Eur. J. 2014, 20, $1669-1676$

(10) (a) Kitagawa, S.; Kawata, S. Coord. Chem. Rev. 2002, 224, 1134. (b) Mercuri, M. L.; Congiu, F.; Concas, G.; Sahadevan, S. A. Magnetochemistry 2017, 3, 17.

(11) (a) Atzori, M.; Benmansour, S.; Minguez Espallargas, G.; Clemente-Leon, M.; Abhervé, A.; Gomez-Claramunt, P.; Coronado, E.; Artizzu, F.; Sessini, E.; Deplano, P.; Serpe, A.; Mercuri, M. L.; 
Gomez García, C. J. Inorg. Chem. 2013, 52, 10031-10040. (b) Atzori, M.; Pop, F.; Auban-Senzier, P.; Gomez García, C. J.; Canadell, E.; Artizzu, F.; Serpe, A.; Deplano, P.; Avarvari, N.; Mercuri, M. L. Inorg. Chem. 2014, 53, 7028-7039. (c) Abherve', A.; Clemente-Leon, M.; Coronado, E.; Gomez-García, C. J.; Verneret, M. Inorg. Chem. 2014, 53, 12014-12026. (d) Abhervé, A.; Mañas-Valero, S.; ClementeLeon, M.; Coronado, E. Chem. Sci. 2015, 6, 4665-4673. (e) Atzori, M.; Pop, F.; Auban-Senzier, P.; Clerac, R.; Canadell, E.; Mercuri, M. L.; Avarvari, N. Inorg. Chem. 2015, 54, 3643-3653. (f) Benmansour, S.; Gomez García, C. J. Polymers 2016, 8, 89. (g) Benmansour, S.; Abhervé, A.; Gomez-Claramunt, P.; Valles-García, C.; Gomez-García, C. J. ACS Appl. Mater. Interfaces 2017, 9, 26210-26218. (h) PalaciosCorella, M.; Fernandez-Espejo, A.; Bazaga-García, M.; Losilla, E. R.; Cabeza, A.; Clemente-Leon, M.; Coronado, E. Inorg. Chem. 2017, 56, 13865-13877. (i) Kingsbury, C. J.; Abrahams, B. F.; D'Alessandro, D. M.; Hudson, T. A.; Murase, R.; Robson, R.; White, K. F. Cryst. Growth Des. 2017, 17, 1465-1470. (j) DeGayner, J. A.; Jeon, I.-R.; Sun, L.; Dinca, M.; Harris, T. D. J. Am. Chem. Soc. 2017, 139, 4175-4184. (k) Benmansour, S.; Perez-Herraez, I.; Lopez-Martínez, G.; Gomez García, C. J. Polyhedron 2017, 135, 17-25. (1) Benmansour, S.; Hernandez-Paredes, A.; Gomez-García, C. J. J. Coord. Chem. 2018, 71, 845.

(12) (a) Imaz, I.; Mouchaham, G.; Roques, N.; Brandes, S.; Sutter, J.-P. Inorg. Chem. 2013, 52, 11237-11243. (b) Benmansour, S.; Valles-García, C.; Gomez-Claramunt, P.; Minguez Espallargas, G.; Gomez García, C. J. Inorg. Chem. 2015, 54, 5410-5418. (c) Sumida, K.; Hu, M.; Furukawa, S.; Kitagawa, S. Inorg. Chem. 2016, 55, 37003705. (d) Murase, R.; Abrahams, B. F.; D’Alessandro, D. M.; Davies, C. G.; Hudson, T. A.; Jameson, G. N. L.; Moubaraki, B.; Murray, K. S.; Robson, R.; Sutton, A. L. Inorg. Chem. 2017, 56, 9025-9035. (13) Taniguchi, K.; Chen, J.; Sekine, Y.; Miyasaka, H. Chem. Mater. 2017, 29, 10053-10059.

(14) (a) Jeon, I.-R.; Negru, B.; Van Duyne, R. P.; Harris, T. D. J. Am. Chem. Soc. 2015, 137, 15699-15702. (b) Darago, L. E.; Aubrey, M. L.; Yu, C. J.; Gonzalez, M. I.; Long, J. R. J. Am. Chem. Soc. 2015, 137, 15703-15711. (c) DeGayner, J. A.; Jeon, I.-R.; Sun, L.; Dincă, M.; Harris, T. D. J. Am. Chem. Soc. 2017, 139, 4175-4184.

(15) (a) Rehwoldt, R. E.; Chasen, B. L.; Li, J. B. Anal. Chem. 1966, 38, 1018-1019. (b) Atzori, M.; Pop, F.; Cauchy, T.; Mercuri, M. L.; Avarvari, N. Org. Biomol. Chem. 2014, 12, 8752-8763.

(16) Atzori, M.; Artizzu, F.; Marchio, L.; Loche, D.; Caneschi, A.; Serpe, A.; Deplano, P.; Avarvari, N.; Mercuri, M. L. Dalton Trans 2015, 44, 15786-15802.

(17) Ashoka Sahadevan, S.; Monni, N.; Abhervé, A.; Auban-Senzier, P.; Canadell, E.; Mercuri, M. L.; Avarvari, N. Inorg. Chem. 2017, 56, 12564-12571.

(18) Ashoka Sahadevan, S.; Monni, N.; Abhervé, A.; Marongiu, D.; Sarritzu, V.; Sestu, N.; Saba, M.; Mura, A.; Bongiovanni, G.; Cannas, C.; Quochi, F.; Avarvari, N.; Mercuri, M. L. Chem. Mater. 2018, DOI: 10.1021/acs.chemmater.8b03399.

(19) Weiss, S.; Krommer, H. Chem. Abstr. 1986, 104, 206730.

(20) Tao, J. M.; Perdew, J. P.; Staroverov, V. N.; Scuseria, G. E. Phys. Rev. Lett. 2003, 91, 146401.

(21) Jensen, K. P. Inorg. Chem. 2008, 47, 10357-10365.

(22) Hariharan, P. C.; Pople, J. A. Theor. Chim. Acta 1973, 28, $213-$ 222.

(23) Frisch, M. J.; Trucks, G. W.; Schlegel, H. B.; Scuseria, G. E.; Robb, M. A.; Cheeseman, J. R.; Scalmani, G.; Barone, V.; Mennucci, B.; Petersson, G. A.; Nakatsuji, H.; Caricato, M.; Li, X.; Hratchian, H. P.; Izmaylov, A. F.; Bloino, J.; Zheng, G.; Sonnenberg, J. L.; Hada, M.; Ehara, M.; Toyota, K.; Fukuda, R.; Hasegawa, J.; Ishida, M.; Nakajima, T.; Honda, Y.; Kitao, O.; Nakai, H.; Vreven, T.; Montgomery, J. A., Jr., Peralta, J. E.; Ogliaro, F.; Bearpark, M.; Heyd, J. J.; Brothers, E.; Kudin, K. N.; Staroverov, V. N.; Kobayashi, R.; Normand, J.; Raghavachari, K.; Rendell, A.; Burant, J. C.; Iyengar, S. S.; Tomasi, J.; Cossi, M.; Rega, N.; Millam, J. M.; Klene, M.; Knox, J. E.; Cross, J. B.; Bakken, V.; Adamo, C.; Jaramillo, J.; Gomperts, R.; Stratmann, R. E.; Yazyev, O.; Austin, A. J.; Cammi, R.; Pomelli, C.; Ochterski, J. W.; Martin, R. L.; Morokuma, K.; Zakrzewski, V. G.;
Voth, G. A.; Salvador, P.; Dannenberg, J. J.; Dapprich, S.; Daniels, A. D.; Farkas, Ö.; Foresman, J. B.; Ortiz, J. V.; Cioslowski, J.; Fox, D. J. Gaussian 09, Revision B1; Gaussian, Inc.: Wallingford CT, 2009.

(24) (a) Tamaki, H.; Zhong, Z. J.; Matsumoto, N.; Kida, S.; Koikawa, M.; Achiwa, N.; Hashimoto, Y.; Okawa, H. J. Am. Chem. Soc. 1992, 114, 6974-6979. (b) Clemente-Leon, M.; Coronado, E.; Lopez-Jorda, M.; Mínguez Espallargas, G.; Soriano-Portillo, A.; Waerenborgh, J. C. Chem. - Eur. J. 2010, 16, 2207-2219.

(25) Okaya, Y.; Pepinsky, R. Acta Crystallogr. 1957, 10, 681-684.

(26) Hartl, F.; Stufkens, D. J.; Vlcek, A. Inorg. Chem. 1992, 31, $1687-1695$

(27) Tholence, J. L. Solid State Commun. 1980, 35, 113-117.

(28) (a) Novak, M. A. J. Magn. Magn. Mater. 2004, 272-276, e707e713. (b) Novak, M. A.; Folly, W. S. D.; Sinnecker, J. P.; Soriano, S. J. Magn. Magn. Mater. 2005, 294, 133-140.

(29) (a) Gunnarsson, K.; Svedlindh, P.; Nordblad, P.; Lundgren, L.; Aruga, H.; Ito, A. Phys. Rev. Lett. 1988, 61, 754. (b) Laiho, R.; Lahderanta, E.; Salminen, J.; Lisunov, K. G.; Zakhvalinskii, V. S. Phys. Rev. B: Condens. Matter Mater. Phys. 2001, 63, 094405. (c) Mattsson, J.; Jonsson, T.; Nordblad, P.; Aruga Katori, H.; Ito, A. Phys. Rev. Lett. 1995, 74, 4305.

(30) (a) Sellers, S. P.; Korte, B. J.; Fitzgerald, J. P.; Reiff, W. M.; Yee, G. T. J. Am. Chem. Soc. 1998, 120, 4662-4670. (b) Kaul, B. B.; Durfee, W. S.; Yee, G. T. J. Am. Chem. Soc. 1999, 121, 6862-6866. (c) Buschmann, W. E.; Ensling, J.; Gütlich, P.; Miller, J. S. Chem. Eur. J. 1999, 5 (10), 3019-3028. (d) Clerac, R.; O'Kane, S.; Cowen, J.; Ouyang, X.; Heintz, R.; Zhao, H.; Bazile, M. J.; Dunbar, K. R. Chem. Mater. 2003, 15, 1840-1850. (e) Krishnamohan Sharma, C. V.; Chusuei, C. C.; Clerac, R.; Möller, T.; Dunbar, K. R.; Clearfield, A. Inorg. Chem. 2003, 42, 8300-8308. (f) Zhang, X.-M.; Li, P.; Gao, W.; Liu, J.-P.; Gao, E.-Q. Dalton Trans 2015, 44, 511-514. (g) Ghosh, S.; Roy, S.; Liu, C.-M.; Mohanta, S. Dalton Trans 2018, 47, 836-844. (31) Mydosh, J. A. Spin Glasses: an Experimental Introduction; Taylor and Francis: London, 1993.

(32) Choi, K. Y.; Wang, Z.; Ozarowski, A.; van Tol, J.; Zhou, H. D.; Wiebe, C. R.; Skourski, Y.; Dalal, N. S. J. Phys.: Condens. Matter 2012, 24, 246001-6.

(33) Greenwood, N. N.; Gibb, T. C. Mössbauer Spectroscopy; Chapman and Hall, Ltd. Publishers: London, 1971.

(34) Shilov, G. V.; Nikitina, Z. K.; Ovanesyan, N. S.; Aldoshin, S. M.; Makhaev, V. D. Russ. Chem. Bull. 2011, 60, 1209-1219.

(35) For example: (a) Lupu, D.; Barb, D.; Filoti, G.; Morariu, M.; Tarina, D. J. Inorg. Nucl. Chem. 1972, 34, 2803-2810. (b) Maeda, Y. J. Nucl. Radiochem. Sci. 2006, 7, R13-R18.

(36) Bhattacharjee, A.; Bhakat, D.; Roy, M.; Kusz, J. Phys. B 2010, 405, 1546-1550.

(37) For a very pedagogic presentation of the basic methodology, see: Launay, J.-P.; Verdaguer, M. Electrons in Molecules: From Basic Principles to Molecular Electronics; Oxford University Press: Oxford, 2014; Chapter 3.

(38) Austin, I. G.; Mott, N. F. Adv. Phys. 1969, 18, 41-102.

(39) Tsuda, N.; Nasu, K.; Yanase, A.; Siratori, K. Electronic conduction in Oxides; Springer Series in Solid-State Sciences; Springer Verlag: Berlin Heidelberg, 1991; pp 163-168. 